PROCEEDINGS OF THE TWENTY-FIRST ANNUAL MEETING OF THE AMERICAN SOCIETY FOR CLINICAL INVESTIGATION HELD IN ATLANTIC CİTY, N. J., MAY 6,1929

Blood Vessels of Non-Inflammatory Origin in Human Heart Valves. By ALBERT W. Bromer, and Louise J. Zschiesche, (by invitation) and JosepH T. WEARN, Boston, Mass.

By a method of procedure not used heretofore, blood vessels have been demonstrated in one or more valves in 74 of a series of 100 human hearts. No heart with the clinical diagnosis of endocarditis or rheumatic fever has been included. A small percentage of the individuals were sufferers of arterio-sclerotic heart disease.

After as much air as possible has been drawn from the coronary system, Weber's or Higgins' India ink, diluted with an equal amount of distilled water, is injected into the coronary arteries under a pressure of $220 \mathrm{~mm}$. of mercury. During the injection procedure, the heart is gently massaged in a tank of physiological saline solution at a temperature of $38^{\circ} \mathrm{C}$. Inability to maintain an air-tight system has probably been a source of error not infrequently.

The valve leaflets of all hearts injected have been rendered transparent by the Spalteholz method for microscopic examination. The mitral valve has presented vascularization in 58 per cent of the hearts injected; the tricuspid valve in 43 per cent; the pulmonary valve in 25 per cent; and the aortic valve in 5 per cent. Leaflets of two or more valves have been successfully injected in 39 per cent of the total number.

The presence of vessels in the valves seemingly bears no relationship to age, the number of vascularized valves of the higher decades being approximately the same as for each of the earliest decades.

The vascularization of the aortic leaflet of the mitral valve is characterized by two or more vessels of goodly calibre descending in a sweeping looping manner from the auriculo-ventricular juncton toward the line of closure, where they join in a meshwork of anastamoses. Occasionally vascular twigs pass to the free margin of the leaflet. In some specimens vessels run upward in the chordae tendineae, stopping short of the free margin of the leaflet, many looping about to return to the papillary muscle. Occasionally, the chordae vessels form anastamoses with vessels in the basal third of the leaflet. Not infrequently, only one of the large descending vessels may be present, injection of the others having possibly failed through blockage with air, blood cells or a large carbon particle. The posterior mitral leaflet is supplied by three or more large vessels descending with loops, arborizations and anastamoses. These vessels lie close to the superior surface of 
the leaflet. In the non-cleared specimens they are not visible on the under side. Histologically, the larger vessels show true arterial structure.

Tricuspid leaflet injections are characterized by extremely fine vascular twigs extending downward 4 to $8 \mathrm{~mm}$. As in the mitral valve, the looping and interlacing arborizations are most impressive. Vessels ending blindly indicate an incomplete injection.

The pulmonary cusp vascularization, as a rule, is limited to the lower one-half or two-thirds of the membranous portion, with fine arterioles and capillaries extending into the cusps proper from along the line of attachment. The filmy texture renders injection most difficult because of collapse or kinking of the delicate vessels.

The capillary architecture of the aortic cusps is approximately the same as that of the pulmonary cusps, with a rich vascular bed in the commissures. Vessels occasionally run along the line of closure to the corpus Arantii. Studies are now in progress to determine whether the relatively small percentage of successful aortic cusp injections may be explained in many instances by the main blood supply being derived from the vasa vasorum rather than from the immediate coronary vessels.

\section{Experiments on the Patency of the Blood Vessels of Nephritic Kidneys Obtained} at Autopsy. By J. M. Hayman, JR., Philadelphia, Pa.

One of the first questions which arise in the study of the physiology of the diseased kidney concerns the capacity of its vessels to permit a normal blood flow. These experiments aimed to distinguish those types of kidney damage in which a mechanical, anatomic obstruction to blood flow exists from those in which the structural condition of the vessels might be regarded as permitting a normal blood flow.

Kidneys obtained at autopsy were perfused with Ringer's solution at 100, 150 and $200 \mathrm{~mm}$. Hg. pressure and the perfusate collected from the renal vein. The results have been compared with roentgenograms of the arterial tree after injection of bismuth and with histological sections.

Since large kidneys permit a greater volume of perfusate per minute than small ones, all data were reduced to flow per gram of kidney per minute. This of course introduces a disturbing factor in kidneys edematous from disease, but this is offset by the advantages of the method in comparing perfusability of different kidneys.

The volume of perfusate per gram of kidney in 18 normal adult kidneys varied from 1.2 to $2.5 \mathrm{cc}$. per minute at $100 \mathrm{~mm}$. $\mathrm{Hg}$. perfusion pressure, from 2.1 to 4.3 cc. per minute at 150, and from 2.5 to 5.5 at $200 \mathrm{~mm}$. pressure. There was no detectable relation between volume of perfusate per gram of kidney and age.

Kidneys showing purely degenerative changes, the so-called nephroses, allowed as great perfusion flows as normal kidneys. This group includes a kidney of pregnancy and one of bichloride poisoning.

Kidneys from 9 cases of benign arteriolarsclerosis showed a decrease in volume 
of perfusate per gram roughly proportional to the degree of sclerosis. Two of these showed only mild changes histologically and the perfusion flows fell within lower normal range. Four kidneys showed moderately advanced changes histologically. One of these gave a perfusion flow within the lower normal limit, the other three distinctly below it. The other three kidneys showed advanced changes and the perfusion flow per gram of kidney was greatly reduced in all. Unfortunately suitable methods are not available for estimating quantitatively the decrease in number of patent glomeruli per gram so that it is uncertain what part decrease in number of perfused units and increased resistance in existing vessels play in the diminished volume of perfusate. Since the relative increase in volume of perfusate with increase in pressure is of the same order in normal and arteriolarsclerotic kidneys, it seems probable that decrease in the number of patent glomeruli is the more important factor.

Two kidneys showing mild acute diffuse nephritis gave perfusion flows below the normal range. Kidneys from 5 cases of chronic glomerulonephritis and uremia showed a marked reduction of perfusate per gram of kidney at all pressures. The average flow per minute was $0.5 \mathrm{cc}$. at $100 \mathrm{~mm}$. pressure, 0.9 at 150, and 1.2 at 200. These flows were of the same order as those found in advanced arteriolarsclerosis.

\section{Capillary Blood Flow in Man during Fever.1 By Frank Fremont-Smith, and} (by invitation) L. RAymond Morrison, and Alexander W. MaKepeace, Boston, Mass.

Direct microscopic observations of the human nailfold capillaries have been made during the febrile reaction produced by the intravenous injection of typhoid vaccine.

Coincident with the onset of the fever there occurs complete stasis in practically every visible capillary. From a normal flow this stasis reaches its climax rapidly, often suddenly, and continues until the fever has nearly reached its height. During the period of stasis cyanosis occurs.

Just before the height of the fever is reached the blood flow in the capillaries begins again, at first slowly, but within a short time becomes enormously rapid with the appearance of capillary pulsation and the disappearance of the cyanosis. The fever now begins to fall. The rapid flow lasts throughout the period of falling temperature and often for many hours afterwards.

This same series of phenomena occurs in malaria and in sodoku (rat-bite fever).

Evidence is brought forward to show that the stasis is produced by constriction of the terminal arterioles.

The local application of heat prevents the occurrence of the stasis, or abolishes the stasis once it has occurred.

At the meeting of this Society in April, 1928, one of us (Fremont-Smith, F., Dailey, M. E., and Thomas, G. W.) presented evidence that dilution of the blood

1 This investigation was aided by a grant from the Ella Sachs Plotz Foundation. 
serum and cerebrospinal fluid occurs during the febrile response to intravenous injection of typhoid vaccine, analogous to the dilution seen in many acute infections.

We have shown that this dilution of the blood serum occurs as a result of retention of ingested water within the organism. No dilution occurs if water is withheld. Water drinking normally results in prompt diuresis. During experimental typhoid vaccine fever, however, (and also in malarial fever) diuresis is delayed from six to twelve hours or longer.

The antidiuretic effect of typhoid vaccine fever begins coincidently with the constriction of the skin arterioles described above. This could be explained by a similar vasoconstriction of the renal vessels. Mendelson, 1883, demonstrated such a vasoconstriction in the kidney during experimental fever in dogs.

The influence of this antidiuretic effect of fever upon the development of cardiac and nephritic edema is discussed.

The Dynamics of the Circulation in Hypertension, and Its Bearing on Therapy. By Soma WeIss and (by invitation) LaUREnce B. Ellis, Boston, Mass.

Few, if.any, systematic studies of the circulation in arterial hypertension have been made. As a result, there exists no adequate knowledge of the function of the circulation in this condition, and, therefore, rational therapeutic measures cannot be applied.

In an endeavor to throw some light on this subject, a group of patients with arterial hypertension, but without evident cardiac failure or kidney damage, were studied, with the object of discovering wherein the physiology of the circulation in hypertension differs from the normal. The arterial blood pressure was determined by the Riva Rocci method; the arteriolar and capillary blood pressure of the vessels of the skin was estimated with modified Recklinghausen capsules; the venous blood pressure was measured by the method of Moritz and Tabora. The vital capacity of the lungs was obtained with a portable spirometer; the cardiac output per minute and per stroke was ascertained by the carbon-dioxide method; the basal metabolism was obtained with the Tissot method. The velocity of blood flow was tested with the radio-active deposit and the histamine methods; and, finally, the blood volume was determined by the dye method. In a group of 16 patients, nearly all of the above measurements were undertaken repeatedly under basal conditions. In an additional group of 30 patients several of the circulatory functions were studied.

These findings indicate that, in essential arterial hypertension, although an abnormally high pressure exists in the arteries and arterioles, the capillary and venous pressures are normal. In other words, there is an abnormally great drop in the pressure gradient between the arterioles and capillaries. Notwithstanding the high pressure in the arteries, the average cardiac output per minute, the stroke volume of the heart, the velocity of blood flow, and the circulating blood volume are slightly less than in healthy individuals. 
The resistance, which has been demonstrated to exist in the arteriolar portion of the vascular circuit, offers a considerable impediment to the cardiac function and markedly increases cardiac work. The development of the high pressure in the arteries may well be a compensatory response on the part of the circulation to reestablish the normal capillary blood flow and nutrition of the tissues.

The basal metabolism averages above the standard for normal persons. The efficiency of exchange of oxygen and carbon dioxide between tissues and capillary blood, judged from the ratio of tissue consumption of oxygen and the corresponding volume of blood flow, is better than in healthy people.

This study indicates that in order to gain beneficial results by means of a reduction of high blood pressure, the arteriolar resistance must be diminished. Therapeutic measures which induce a lowering of the blood pressure by lessening cardiac output or decreasing blood volume cannot be of permanent benefit.

Cardiotachometric Studies of the Neurogenic Regulation of Ventricular Rate in Auricular Fibrillation. By ERNST P. BoAs, New York, N. Y.

The ventricular rate of patients with auricular fibrillation has been studied by means of the cardiotachometer. It has been shown that the ventricular rate is very variable, that it accelerates in response to the slightest exertion or emotion, and that it slows during rest and particularly during sleep. All of the evidence indicates that the ventricular rate in these patients is under control of the cardiac nerves, and that alterations in rate are governed by neurogenically determined changes in conductivity of the specific conducting tissue of the heart. The changes in ventricular rate arise, apparently, in response to the varying physiologic needs of the body, just as in health, but the reaction is not so well regulated and is often excessive.

Patients with auricular fibrillation may be classed in two groups-those with labile and with stable ventricular rates. The former are high strung and nervous and correspond to patients with neurocirculatory asthenia. Their ventricular rates tend to be rapid, and quantities of digitalis in excess of the body weight dose are required to keep the ventricular action slow and stable. In addition it would seem that sedative and psychotherapeutic treatment would assist materially in slowing the ventricles. In the stable group the ventricles do not exhibit such an exaggerated response to physical and emotional stimuli, and can be readily kept under control by the usual methods of digitalis therapy.

The value of rest and sleep in the treatment of patients with auricular fibrillation, a fact well known, is forcefully demonstrated by actual count of the number of heart beats by means of the cardiotachometer.

Observations upon the Refractory Period of the Normally Beating Mammalian Heart. By E. Cowles Andrus and Edward P. Carter, Baltimore, Md.

Previous determinations of the refractory period of the mammalian auricle have involved driving the heart with a series of break induction shocks at a rate neces- 
sarily more rapid than that of the spontaneous rhythm. The local stimulating effect of these repeated shocks has made accurate measurements possible only upon the atropinized heart, and in many instances, has led to false responses.

Using a specially designed apparatus the authors have determined the refractory period of the normally beating dog's heart. The action current is led off from the auricle, amplified to 12 to 20 volts, and applied to a light relay. Activation of the relay releases a pendulum which in turn throws in a single break induction shock at an interval controlled by the position of a tumble switch along its arc. By this means the normal excitatory process is utilized to control the timing of the interrupting shock. In contrast to earlier measurements the results of the authors show a sharp point above which each stimulus produces a response and below which excitation fails to occur.

A second difficulty in refractory period determinations in the past has been the necessity of introducing the interrupting shock at some distance from the recording electrodes on account of danger to the galvanometer string. This has been overcome by the use of a balanced circuit with a double induction coil as the source of stimulus and by grounding the proximal lead. With such a circuit it has been possible to place the stimulating electrodes actually astride the proximal lead.

A series of measurements has been made under a variety of conditions. The refractory period of the normal dog's auricle has been found to be between 0.08 and 0.12 second. Stimulation of the vagus brings about conspicuous shortening to 0.05 second or even less. A single dose of atropine sufficient to paralyze the vagus causes the refractory period to lengthen. Slow intravenous infusion of adrenalin produces considerable shortening but not to the degree noted under vagal stimulation. Moreover these changes in refractory period are not proportional to alterations in rate; in the case of vagus stimulation and paralysis, rate and refractory period vary in opposite directions.

It has been repeatedly observed that a stimulus introduced shortly after the end of the refractory period, during vagal stimulation, is followed not by a single response, but by auricular fibrillation. Such results have been reported by de Boer and others but always in hearts deprived of their blood supply or poisoned with various drugs and never under vagus stimulation alone. This suggests two points of interest: (1) Focus of stimulation-in every case the stimulus was applied well out upon the auricular appendix. (2) This rhythm followed stimuli which, in the absence of vagus stimulation, would have fallen within the refractory period. Due to shortening of the refractory period by the vagus they fell upon tissue which was excitable but in which recovery of conductivity had presumably not yet returned to normal. Hence as long as vagal stimulation was continued there existed in the auricular musculature, the conditions favorable to a re-entrant rhythm. The fact that under conditions of increased vagus tone, an extrasystole occurring early in diastole may lead to a re-entrant rhythm is, it seems, significant as a possible explanation of the genesis of auricular fibrillation. 
Orthopnea: Its Relation to the Increased. Venous Pressure of Myocardial Failure. By A. Carlton Ernstene (by invitation) and Herrman L. Blumgart, Boston, Mass.

The factors, which impel patients with myocardial failure of the congestive type to sit up in bed, have aroused the curiosity of many investigators. Insufficient attention, however, has been paid to the rôle of increased venous pressure in causing this phenomenon. The mechanism producing orthopnea in a patient with increased venous pressure due to uncomplicated congestive failure we believe to be as follows. Increased pressure within a vein causes slowing of blood flow in the corresponding capillary tributaries. If a patient with cardiovascular failure and a right auricular pressure equivalent to $15 \mathrm{~cm}$. of water should lie flat in bed, the veins about the respiratory center would have a corresponding pressure of 15 $\mathrm{cm}$. and the blood flow would be diminished. If, however, he should sit up so that the respiratory center were $15 \mathrm{~cm}$. above the right auricle, the pressure within the veins leading from the respiratory center would be zero. The blood flow in the capillaries feeding these veins would then be increased, and the respiratory center might be expected to receive a more adequate blood supply. This should lessen subjective respiratory distress.

To test the validity of this theory, 82 comparisons of the height of venous pressure and the degree of orthopnea have been made in 21 patients with uncomplicated myocardial failure. The venous pressure was measured by the direct venepuncture method of Moritz and Tabora, and the degree of orthopnea was estimated by measuring the perpendicular distance between the right auricle and a point corresponding to the respiratory center, the external occipital protuberance. A parallelism between these measurements was, in general, observed: the higher the venous pressure, the greater the orthopnea.

Moreover, with the patient flat in bed, simple elevation of the head by flexing it on the thorax conspicuously diminished the respiratory distress in practically every instance. No other theory of orthopnea accounts for this phenomenon.

These and other observations indicate that, while other mechanical factors are not without importance, in uncomplicated myocardial failure the orthopneic position reduces subjective discomfort by releasing the respiratory center from the effects of increased venous pressure. This mechanism we believe to be of fundamental importance in the pathogenesis of orthopnea.

Experimental Edema. By Louis LeIter (by invitation) and FrankLIN C. MCLEAN, Chicago, Ill.

The well known association of low plasma proteins with certain forms of clinical edema and the concept of Starling that the osmotic pressure of the plasma proteins determines the reabsorption of tissue fluids into the capillaries, suggested the production of experimental chronic hypoproteinemia.

Dogs were bled 400 to $500 \mathrm{cc}$. twice daily from the heart and a corresponding volume of erythrocytes suspended in an alkaline Locke's solution was reinjected 
intravenously. Fifteen hundred cubic centimeters of 0.85 sodium chloride solution were given daily by stomach tube. The concentration of plasma proteins was determined by the usual micro-Kjeldahl methods.

Definite subcutaneous edema with gain in weight appeared by the fifth day in all of the dogs whose plasma protein level fell to about 3 per cent or less. Ascites usually occurred at about the same time. The edema ordinarily involved the external genitals, thighs, buttocks, perineum, and lower abdomen. Discontinuance of bleeding for twenty-four hours led to prompt rise of the plasma proteins and rapid disappearance of edema in spite of continued administration of saline. The entire cycle could be repeated on further plasmaphoresis.

The subcutaneous edema and ascitic fluids resembled nephrotic edema fluid in appearance, with extremely low protein content-usually less than 0.1 per cent in the former and about 0.25 per cent in the latter. This composition definitely ruled out the increased capillary permeability which is the cause of other types of experimental edema.

Control experiments were made to rule out cardiac damage, under-nutrition, and high salt and water intake per se; all with negative results. Plasma protein depletion alone does not lead to edema; hence, as in clinical edemas, the salt intake is an important factor. This experimental edema was apparently on an extrarenal and mechanical basis analogous to that seen in some forms of Bright's disease and in undernutrition (war edema and cachectic edema).

The Effect of Edema on Oxygen Utilization. By T. R. HARRISON and (by invitation) Совв PILcher, Nashville, Tenn.

The oxygen content of arterial blood and of blood from the femoral veins has been studied in patients with heart disease and in individuals without circulatory disorders. The utilization (arteriovenous difference) is less in patients with cardiac edema than in the control group. Average values for numerous analyses were:

\begin{tabular}{|c|c|c|c|c|c|}
\hline \multicolumn{4}{|c|}{ Cardiac patients } & \multirow{2}{*}{$\begin{array}{l}\text { Normal } \\
\text { controls }\end{array}$} & \multirow{2}{*}{$\begin{array}{c}\text { Non-cardiac } \\
\text { edema }\end{array}$} \\
\hline Marked edema & Moderate edema & Slight edema & No edema & & \\
\hline 4.08 & 5.15 & 5.44 & 6.52 & 7.73 & 4.22 \\
\hline
\end{tabular}

There were two exceptions to these general findings. In patients with (a) digitalis intoxication or $(b)$ acidosis, the utilization was high, whether edema was present or not.

The low utilization in patients with edema was noted whether they were gaining or losing edema. These observations are interpreted as follows: Since there is hyperoxemia of the femoral venous blood in patients with edema of the legs, increased blood flow through the edematous legs seems probable. This may be due to local oxygen lack in the tissues if, as seems likely, edema in the tissues, as in the 
lungs, causes a partial obstruction to the passage of oxygen through the capillary wall. Hence, the oxygen pressure may be raised in the blood and lowered in the tissues. It seems that edema per se throws an additional strain on the heart by causing additional circulation to the edematous tissues and hence, that a vicious cycle may ensue. Therefore it is probable that the cardiac patient suffers not so much from cardiac insufficiency as from circulatory inefficiency.

It should be emphasized that the results found seem to be primarily effects, and only secondarily causes of edema.

\section{A Study of Serum Inorganic Sulfates in Renal Insufficiency. By E. G. WAREFrELD (by invitation) and N. M. KEITH, Rochester, Minn.}

Further Studies on Deposit Nitrogen. By G. P. GrabField, Boston, Mass.

In the attempt to apply previous studies on the mobilization and excretion of nitrogen in the body by means of iodides and salicylates to patients with chronic Bright's disease, it was found that patients showing the nephrosis syndrome excreted large amounts of nitrogen in proportion to the sulphur excretion. In comparing cases of Bright's disease without edema with those presenting the nephrosis syndrome, it was found that the former excreted urine, presenting the normal nitrogen-sulphur ratio, and that these patients tended to exhibit negative sulphur balance. Patients presenting the nephrosis syndrome, on the contrary, showed a strong tendency to retain sulphur as compared with their retention of nitrogen. Such patients retained as much as 85 per cent of the sulphur of the diet. In a general way, of the patients presenting the nephrosis syndrome those that retained on high protein diets most sulphur in relation to the retention of nitrogen, showed the best clinical results in loss of edema and sense of well-being.

These patients were kept for long periods on diets constant as to nitrogen, sulphur and phosphorus. The water intake was controlled and kept at a definite level by calculating the water content of the food and adding sufficient fluid to the diet to make a constant volume.

It was found that many of these cases were mixed and that some approached on lower protein diets the ideal condition in relation to nitrogen and sulphur retained.

The basis for further study of the sulphur metabolism in Bright's disease has been laid by these experiments, and it seems not unlikely that this component of the protein molecule will prove to be a factor of greater importance than it has hitherto been considered to be.

Liver Fractions in Pernicionas Anemia. By RANDOLPH West, and (by invitation) Marion Howe, New York, N. Y.

We have shown that the substance in liver effective in pernicious anemia is precipitable by phosphotungstic acid but not by silver even in alkaline solution. The process now used is as follows: 
Four hundred grams of Lilly Liver Extract is dissolved in $600 \mathrm{cc}$. water and to this 200 grams anhydrous $\mathrm{Na}_{2} \mathrm{SO}_{4}$ are added. After filtering off the precipitate which forms, sufficient 95 per cent alcohol is added to the filtrate to give a final concentration of 60 per cent. The supernatant alcoholic fluid is poured off within a few minutes after adding the alcohol and filtered. Alcohol is blown off from the filtrate with a hair dryer till volume is about $500 \mathrm{cc}$. The Kossel silver fractionation is then carried out using silver lactate and baryta, and excess silver removed from the filtrate as sulphide or chloride and baryta as sulphate. To the silver filtrate 3 per cent by volume $\mathrm{H}_{2} \mathrm{SO}_{4}$ is added, and then a moderate excess of phosphotungstic acid (Kahlbaum): The phosphotungstic precipitate is dissolved in 75 per cent acetone and decomposed with hot aqueous baryta and filtered at the pump. Excess baryta is removed as sulphate, acetone blown off, and the material is ready for feeding. Yield about 3 to 4 grams solids. This fraction has never failed to give positive results on feeding in pernicious anemia. The best preparation fed to a case of tropical sprue in doses of 0.5 gram daily for eight days gave a reticulocyte peak of 200,000 per cubic millimeter, red blood cells being about 1.9 million. The poorest preparation fed in doses of 1.5 gram daily to a case of pernicious anemia gave a reticulocyte peak of 360,000 per cubic millimeter with red blood cells at 1.2 million. This is known as fraction B. It gives positive biuret, indole and diazo reactions, also a positive "arginine" reaction with a naphthol and sodium hypochlorite.

On treating fraction "B" with mercuric acetate at $\mathrm{pH} 6.0$ practically all material precipitable with phosphotungstic acid is removed from the solution, but on regeneration of the precipitated bases with $\mathrm{H}_{2} \mathrm{~S}$ and feeding in 0.6 gram doses daily we have had negative resutls (one case tropical sprue with prompt response later) to 12 grams Lilly Extract daily.

On adjusting fraction $\mathrm{B}$ to $\mathrm{pH} 7.0$, and adjusting volume so that the material derived from 800 grams Lilly Extract was in $100 \mathrm{cc}$. water, and pouring this into $900 \mathrm{cc}$. of acetone, the biuret positive material was largely precipitated. A case of pernicious anemia was given $1.5 \mathrm{gram}$ of this precipitate, derived from several kilograms of Lilly Extract, daily for eight days with a negative result, and later responded well to liver. The acetone soluble material, after blowing off acetone, gave a strong diazo and indole reaction and an extremely faint biuret. This in doses of 0.6 and 0.8 gram daily has given weak positives (reticulocyte peaks of about 140,000 per cubic millimeters with red blood cells below 2.0 millions) in two cases, and a negative in one case.

On evaporating fraction $\mathrm{B}$ to small volume and making up to $100 \mathrm{cc}$. (material from $\mathbf{4 0 0}$ grams Lilly) with absolute alcohol to give final alcoholic concentration of 74 per cent and treating with an excess of alcoholic platinic chloride a precipitate formed which on regeneration with $\mathrm{H}_{2} \mathrm{~S}$ and reprecipitation with platinic chloride was crystalline. The platinum content and the melting point of the aurichloride and mercurichloride agree with those of choline. Mixed melting point with known choline aurichloride showed no depression. An insoluble iodide, 
resembling choline iodide in crystal form was also observed. On feeding this base in doses of about $700 \mathrm{mgm}$. daily for ten days to a case of pernicious anemia with red blood cells at one million per cubic millimeter the reticulocytes rose from 4.2 to 11.4 per cent. This material had been through platinum but once, and was derived from $4 \mathrm{kgm}$. of Lilly Extract. The effect was probably due to impurities accompanying choline. A second case fed $120 \mathrm{mgm}$. daily of material, twice through platinum, showed on the eleventh day of feeding a rise of reticulocytes, from 1 to 7 per cent with red blood cells at 1.0 million.

The platinum mother liquor, after removing $\mathrm{Pt}$ with $\mathrm{H}_{2} \mathrm{~S}$, on feeding 5.5 grams in one dose gave a reticulocyte peak of 150,000 per cubic millimeter with red blood cells at 1.7 million.

Synthetic choline, on feeding six grams in three days gave no reticulocyte response on the seven days following, whereas feeding 72 grams Lilly Extract in two days gave a reticulocyte peak of 300,000 per cubic millimeter with red blood cells at 1.2 million on the seventh day after feeding.

Fraction B has retained its full activity after removing all material precipitable with picric acid (4 grams solids in $20 \mathrm{cc}$. solution saturated with solid picric acid) and after shaking with butyl alcohol in both acid and alkaline solution.

Serum Iron Studies. By Herman H. RIecker and Mary E. Winters (by invitation) and Henry Field, JR., Ann Arbor, Mich.

The object of this study was to determine whether or not a relationship existed between (1) the level of serum iron, hemoglobin production, and iron administration in the experimental anemia of hemorrhage; (2) the level of serum iron and the iron metabolism in pernicious anemia during active remission; and (3) the serum iron content and the hemoglobin percentage in various secondary anemias.

Iron determinations were made by Elvejhem's and Hart's modification of the Thompson method. The element of error possible from hemolysis was avoided by precipitation of the serum proteins with trichloracetic acid, following the suggestion of Briggs.

The animal experiments were conducted upon dogs by a method essentially similar to that devised by Whipple and Robscheit-Robbins.

The following relations were noted: As the anemia progressed there occurred a depression in the serum iron level from the normal of about $1.2 \mathrm{mgm}$. per $100 \mathrm{cc}$. of blood to between 0.7 and $0.9 \mathrm{mgm}$. during which time the animal did not regenerate hemoglobin. When $\mathrm{Fe}$ was added to the diet in any form regeneration began and the serum iron level definitely rose.

Then a series of six pernicious anemia cases were studied during relapse and remission. Blood serum iron determinations were made and the intake and excretion of iron were determined. The serum iron figures were all above, or within, the normal limits.

The iron excretion of patients before treatment on a constant intake of 7 to 15 mgm. was found to be fairly constant, as was the control case. However, when 
treatment was begun with liver extract a marked increase of excretion over intake occurred and continued throughout the periods of observation.

In the secondary anemias those due to hemorrhage were separated from those of an unidentified nature. In cases with acute hemorrhage the serum iron levels were in general lower than in the other types. The studies in secondary anemia have not been completed so that the results given merely indicate the trend of the investigation.

Conclusions. 1. In the experimental anemia of hemorrhage a definite iron starvation is present and this is relieved by iron feedings with a rapid increase in hemoglobin production. Serum iron determination may be used to detect this condition.

2. In pernicious anemia there is a well marked negative iron balance during the remission induced by liver extract. The serum iron levels tend to be increased above the average normal in relapse, and to approach the normal in remission.

3. No degree of iron stravation could be found in secondary anemias comparable to that in experimental animals with anemia due to hemorrhage.

The Endogenous Uric Acid Metabolism in Pernicious Anemia. Matruew C. RmDle, (by invitation) and Cyrus C. Sturgis, Ann Arbor, Mich.

The endogenous uric acid metabolism was studied during early remission in twelve patients with pernicious anemia, using purine-poor diets over periods of 10 to 75 days.

Before treatment, in two patients the concentration of uric acid in the blood serum was higher than normal, in three it was normal, and in six lower than normal. Only one patient excreted increased amounts of uric acid before treatment.

During remissions induced by liver extract therapy there was an increase in the urinary excretion of uric acid of from 74 to 531 per cent and an increase in concentration of uric acid in the blood serum of from 28 to 239 per cent which was correlated with the rise in percentage of reticulocytes. The increased uric acid metabolism was shown to be endogenous in nature by the failure of impotent liver extract to produce the typical results, by the typical uric acid increase both following the administration of a single massive dose of liver extract and during spontaneous remission and by the failure of liver extract to increase the uric acid metabolism in a normal person.

The increased uric acid metabolism may be associated with the increased rate of destruction of red blood cell nuclei and a general increase in nuclear metabolism during remission.

Calcium Metabolism in Hyper- and Hypo-Parathyroidism. By H. A. BuLGER and D. P. BARR, St. Louis, Mo.

Recent advances in our knowledge of calcium metabolism, especially those afforded by Collip's parathyroid extract, have placed us in a position to recognize the clinical picture of hyperparathyroidism. Extensive study of two such patients 
has revealed typical symptoms and associations, together with characteristic abnormalities of calcium metabolism. More calcium than ingested was excreted by the intestines alone, although there were also excessive amounts in the urine. There was a negative phosphorus balance.

A great reduction in calcium in the urine and a positive calcium balance could be obtained by administration of phosphates.

These abnormalities were compared with and were in striking contrast to those found in hypoparathyroidism, in which there have been almost negligible amounts of calcium in the urine and a remarkable tendency to retain calcium.

One patient with hyperparathyroidism was studied in all stages of transition to extreme hypoparathyroidism which followed the removal of a parathyroid tumor.

The Specific Dynamic Action of Protein in the Obese. By E. F. Du Bors and (by invitation) H. J. Spencer, W. S. McClellan and E. FALK, New York, N. Y. One explanation of obesity is that the specific dynamic action of food stuffs is below normal. There is considerable doubt, judging from the literature, whether this is a fact. We have studied the influence of protein in obese and normal individuals by means of the respiration calorimeter.

Twelve observations following meals of 300 to 500 grams of lean meat were made on 4 obese and 3 normal men of various ages who were studied for considerable periods in the metabolism ward. These observations show considerable variation in the heat output from hour to hour both in the individual records and in the group averages. The extra heat production, expressed as percentages of the basal heat out-put, has been calculated hourly from the time the meat was ingested.

The average increase in caloric output of the obese men surpassed the normal in the fourth hour. The normal men put out heat more uniformily. The average surplus heat output per hour was approximately 13 per cent for the obese, and 17 per cent for the normal men.

Our impression is that, while the obese man responds to protein more irregularly than the normal man, his extra heat output is not significantly different from the normal.

The Effect of Lessened Respiratory Reserve on the Blood and the Circulation: An Experimental Study. By WiruIs S. Lemon, Rochester, Min.

A series of experiments was carried out with the object of observing the effect of lessened mechanical efficiency on respiratory reserve. It was hoped also to discover the point at which reserve is lost, respiration as a function becomes inadequate and circulatory aid is required to maintain comfortable existence. The animal studied was an intelligent dog which had previously been taught to lie quietly while wearing the mask usually employed for basal metabolic estimations.

At approximately weekly intervals during March and April of 1927, the dog was subjected to four operations carried out under ether anesthesia and aseptic tech- 
nic. These operations were: (1) evulsion of all the left intercostal nerves; (2) evulsion of the lower eight right intercostal nerves; (3) evulsion of the right phrenic nerve, and (4) evulsion of the left phrenic nerve.

As a result of this procedure, respiration depended on the actions of the muscles attached to the ribs posterior to the operative sites, and those extra-respiratory muscles about the neck and shoulders which are used normally only following extreme muscular exertion. The respiratory function of the diaphragm was of course excluded, and its effect on intraabdominal pressure removed; its only rôle was that of a partition separating thorax from abdomen.

The behavior of the dog following surgical interference was in every respect similar to that observed in a previously reported group of experiments. As a result of section of the intercostal nerves on one side, there was immediate or delayed, temporary or persistent, asymmetry of the chest, with a definite and measurable loss in outward movement of the costal arch and margin during inspiration. The reduction amounts to from 30 to 50 per cent of normal, depending on the number of nerves cut. When half the diaphragm is paralyzed, no outward movement of the costal arch margin occurs during inspiration. Symmetric reduction of movement results from bilateral section of the intercostal nerves, and regardless of the order in which phrenic nerve paralysis is introduced, the movements remain the same. The animal of the present experiment after operation lived comfortably, played about like its normal mates and on casual examination could not be distinguished from them. It could not, however, respond to vigorous exercise with the same ease owing to the limitation of vital capacity.

In accordance with the object of this investigation, the intake of air for each unit of time was measured both before and after the series of operations, since it was believed the results would be equivalent in value to alterations in volume. The figures indicated that the respiratory function was adequate to supply suffcient ventilation under all conditions and that the vital capacity provided for a normal amount of tidal air.

The animal was returned to the kennels and apparently lived a normal life during the following year. Despite the paralysis of the whole diaphragm and upper abdominal muscles, difficulty in urination or in defecation was not observed. The lower abdominal muscles, however, had undergone hypertrophy.

Exactly one year after the last operation, the abdomen was opened. The diaphragm was found to be high in the thorax and so thinned that the lungs were plainly visible through it. Specimens from each leaf of the diaphragm were removed for study. After the animal had recovered from the operation, it was observed that as the chest was raised during inspiration, the lower abdominal muscles contracted strongly. This suggests a compensatory attempt to retain the abdominal contents in the abdomen, thus preventing respiratory embarassment.

Twenty months after the first operation, the blood was studied to determine whether or not the long continued reduction in vital capacity could have brought 
about erythrocytosis, changes in blood volume, in hematocrit values, in hemoglobin, in oxygen, in carbon dioxide, or in the blood count. Electrocardiographic tracings were also made. Repeated calculations and comparisons with values obtained in normal dogs did not reveal significant alterations in the experimental animal. This confirms the opinion that the animal retained sufficient respiratory reserve and under ordinary living conditions did not require assistance from the circulation.

At the end of February, 1929, a second laparotomy was performed. After the adhesions were separated, it was found that the stomach, part of the duodenum and all but two of the lobes of the liver had migrated up into the thorax; this confirmed previous roentgen-ray data. The part of the diaphragm which yet remained was, as previously described, thin and translucent and flapped back and forth with respiratory movements. An incision through its costal attachments was made on each side thus eliminating its action as even a partition. The abdomen was then closed and on recovery from the anesthetic the dog ran about the room without any apparent respiratory embarrassment. A regimen of rest was imposed to encourage healing and particularly to allow development of compensation and to avoid unnecessary strain.

Examinations of the blood, March 8 and 16, showed, respectively, hemoglobin 85 and 90 per cent, erythrocytes $4,910,000$ and 5,760,000 and leukocytes 15,900 and 12,400 for each cubic millimeter. The differential count was essentially normal as also was the percentage volume of erythrocytes. The air intake each minute was somewhat larger than previously, being 4.56 liters as compared with 3.18 preoperatively. The respiratory rate each minute had increased to 22 from a preoperative average of 12 . The pulse rate remained the same. Hematocrit varied from 42 to 45 per cent of cells. Blood volume was $86 \mathrm{cc}$. per kilogram. The electrocardiogram was normal.

Summary. Vital capacity has been lessened, but never beyond being equivalent to tidal air; ventilation volume was raised somewhat, but never to an abnormal degree. The hemoglobin remained within the normal limits as also did the hematocrit percentages. Although the oxygen saturation of both arterial and venous blood was lowered, the arterial and venous oxygen content was essentially normal. There was no erythrocytosis and the heart showed no evidence of abnormality.

These findings would seem to confirm the independence of the fundamental functions of the cardiac and respiratory systems, great loss of reserve in one ,being necessary before demonstrable evidence of coöperative support is provided by the other.

The Experimental Production of Chronic Abscess of the Lung. By LouIs G. HERRMANN, (by invitation) and ElliotT C. CuTler, Cleveland, Ohio.

A study of the factors that are responsible for the chronicity of the suppurative processes of the lung was made. The marked increase in the intrabronchial pressure associated with constant violent cough has been shown to play a minor 
rôle in the prolongation of the activity of these pulmonary lesions. In the experiments previously reported from this laboratory only aerobic microörganisms were implanted in the pulmonary tissue by means of the vein-segment embolus. The lesions that resulted were all of the acute type and they healed spontaneously within three weeks.

Recently Smith showed that the bacteria present in chronic abscess of the lung in human beings were morphologically identical with the bacteria present in the material from the margins of the gums of patients with pyorrhoea alveolaris.

A detailed study of this material was made and the embolic method of implantation of this material into the pulmonary tissue was utilized in a series of 38 dogs. With one exception each animal developed a localized abscess at the site of lodgment of the embolus. Of the 38 dogs 28.9 per cent developed pulmonary abscesses which remained active for more than five weeks. In two of the animals the lesions remained active for 101 days and 126 days respectively. At autopsy the cavities of the abscesses were filled with grayish-green necrotic material that had a very foul odor. There was a thick wall of induration about the cavity of the abscesses.

The material from these experimentally produced chronic pulmonary lesions was cultured on a great variety of culture media and under both aerobic and anaerobic conditions. In all, twelve different varieties of microörganisms were isolated in pure culture,-five aerobic microörganisms and seven anaerobic microorganisms.

These pure cultures of microörganisms were then implanted into the pulmonary tissue of another series of dogs. The aerobic organisms produced only acute lesions that healed spontaneously within three weeks. The lesions that resulted from the implantation of the anaerobic microörganisms in the pulmonary tissue were of longer duration and several of them remained active for more than five weeks. Pure cultures of the Spirochaeta microdentium and the large and small variety of fusiform bacilli were also implanted in the pulmonary tissue but no lesion developed at the site of lodgment of the embolus.

Several combinations of these anaerobic microörganisms were used and the lesions that were produced more closely resembled the true chronic abscesses of the lung which are found in man.

Our studies show that the anaerobic group of organisms are the important factors that determine the chronicity of pulmonary lesions. Further experiments are being conducted with the hope of determining the exact combination of anaerobic microörganisms that is responsible for the chronicity of these lesions.

The Flora of the Upper Respiratory Tract of Infants in the First Year of Life. By YALE KNeELAND, JR., (by invitation). and A. R. Dochez, New York, N. Y.

In connection with studies on the common cold, it was thought advisable to investigate the upper respiratory flora of infants. This report is based on data derived from thirty normally-delivered infants in Sloane Hospital; a number of 
these were subsequently followed in the out-patient department, and observations were also made on infants of the same age with and without colds. As a rule the upper respiratory tract is sterile at birth, no growth being obtained in 85 per cent of the nasal cultures, and 80 per cent of the throats in the first day of life. After the first feeding, however, bacteria are regularly found in the throat, although the nose may remain sterile for another 24 hours. Growth from the nose is rarely abundant, the Staphylococcus albus being the most prominent organism. Diphtheroid bacilli rank next, with Staphylococcus aureus and large Gram-positive cocci following. Streptococci are relatively less frequent, occurring in but 19 per cent of all cultures. Members of the colon group and Gram-negative cocci are rarely encountered. From the throat growth is usually abundant with streptococci the outstanding organism, the indifferent (gamma) type being more frequent than the green-producing varieties. Staphylococci are also very common. Colon bacilli are occasionally seen, while diphtheroid bacilli and Gram-negative cocci are rare. In the first two weeks of life, $B$. pfeifferi, pneumococcus and hemolytic streptococcus were never encountered either in the nose or throat.

For comparison with this group, twenty-eight normal infants from four to eight months of age were studied, and certain differences noted. In the nose the staphylococci were less outstanding, with a corresponding rise in the Gram-negative cocci (18 per cent as opposed to 1 per cent in the new-born), and the appearance of $B$. pfeifferi and pneumococci in 7 and 14 per cent of the cases respectively. The throat showed a marked increase in the green streptococci, which appeared in 100 per cent of cases, at the expense of indifferent streptococci and staphylococci. The incidence of Gram-negative cocci went from 4 per cent to 71 per cent, and $B$. pfeifferi was found in $\mathbf{5 3}$ per cent of cases. Hemolytic streptococci appeared in 11 per cent. (Nineteen of these normal infants gave a history of having had colds and nine did not; there was no difference between the two save for a somewhat higher incidence of Gram-negative cocci in the throats of the former.)

Observations were also made on twenty-one infants early in the course of their first colds, the average age being three months. There was no essential difference between their flora and that of the normal group, with the exception that they showed a higher incidence of diphtheroid bacilli, and pfeiffer less frequently. From a clinical standpoint, these first colds are mild, characterized by a moderate degree of coughing and sneezing, with at times a little coryza, usually without constitutional symptoms.

Lastly, a group of fourteen infants with recurrent colds were studied, the average age being seven months. One striking change was noted from the normal controls, namely the increase of $B$. pfeifferi and pneumococci in the nasal cultures to 21 and 43 per cent respectively. The latter was actually predominant in 36 per cent of cases. It may be added that many of these children had a purulent nasal discharge, and sinusitis was not improbable. The flora of the throat remained unchanged.

From the evidence thus far obtained, it would appear unlikely that there is any 
specific bacterial incitant of the early colds of infancy, although in the chronic recurrent type of cold bacteria probably play a part. On the other hand, such pathogens as $B$. pfeifferi, pneumococcus, and hemolytic streptococcus may occur in normal infants without giving rise to symptoms.

Chloride Balance in Pneumonia..$^{1}$ By J. H. Austin and (by invitation) F. W. Sunderman, Philadelphia, Pa.

The intake and output of chloride have been measured in seven patients with lobar pneumonia. Four of these patients received the usual diet and therapy; three received large amounts of sodium chloride ( 8 to 30 grams per day) by mouth during the precritical period. In the first group although during the precritical period excretion of chloride in the urine was very low nevertheless the total excretion of chloride exceeded the intake. In the second group the excretion of chloride in the urine was increased but was less than in normal subjects. In the second group there was consistently retention of chloride before the crisis. Our studies support the view that lobar pneumonia is characterized during the precritical period by a diminished capacity to conserve chloride on a low intake of chloride and a diminished capacity to excrete chloride on a high intake of chloride.

The Experimental Reproduction of the Blood Picture of Infectious Mononucleosis in the Guinea Pig. By L. W. GorhaM and (by invitation) Davm T. SMnth and H. D. Hunt, Albany, N. Y.

Infectious mononcleosis is a benign sporadic disease occurring in young adults, and is characterized by fever, sore throat, and enlargement of the glands and spleen. Although Turck studied a case in 1907 the real interest in this disease dates from the contribution of Sprunt and Evans in 1920.

The frequent occurrence of sore throat in these cases suggested that the infectious agent either remained localized to the pharynx or entered the body through the pharynx. Some of the cases present typical Vincent's angina of the pharynx, while others do not.

The first case studied was a typical case of infectious mononucleosis in a young girl who had a very severe Vincent's angina of the tonsils. Some of the membrane from the pharynx was inoculated into the groin of two guinea pigs and both animals developed the typical blood picture of infectious mononucleosis. Dr. H. D. Hunt developed infectious mononucleosis subsequent to his contacts with the patient and with the infected guinea pigs. The mother of Dr. Hunt also developed the disease apparently as the result of direct contact. Material removed from the throat of Dr. Hunt with a suction apparatus produced the blood picture of the disease in the guinea pigs. Later in the experiments Miss R., who was counting the blood of the infected guinea pig, developed infectious mononucleosis. Material removed from her throat also produced the typical blood picture in

1 This investigation was aided by a grant from the Ella Sachs Plotz Foundation. 
guinea pigs. So the blood picture of the disease has been reproduced in guinea pigs with material from the pharynx of three different cases. One of these had a typical Vincent's infection of the throat, one had a typical Vincent's infection but the throat did not have Vincent's infection.

An examination of Dr. H. D. Hunt's throat in the early stage of the disease revealed a very large number of vibrios. Since very little is known of the blood reaction to vibrios we decided to isolate and study this organism first. Two strains were isolated; One from a case of Vincent's angina and one from a case of acute Vincent's infection of the bronchi. Both these strains produced typical blood pictures in the guinea pig. One of these strains was used only as a dead heatkilled vaccine. This dead material produced just as typical changes in the blood as did the living organism of the other strain. After recovering from one attack the animals were immune to a second or third inoculation. There was cross immunity between the two strains. Blood from Dr. Hunt agglutinated a vibrio from a different source in a dilution of $1: 64$. Two cubic centimeters of this serum prevented the appearance of the blood changes in the guinea pig for one week, after which time the typical changes appeared. A rabbit was immunized to the vibrio and its blood agglutinated the organism in a dilution of $1: 320$. Five cubic centimeters of this serum prevented the development of the blood changes in a guinea pig inoculated with 2 cc. of a vibrio culture. Five cubic centimeters of blood from a normal rabbit failed to protect a guinea pig inoculated with the same amount of same culture.

Cultures of (1) fusiform bacilli, (2) Streptothrix (3) Staphylococcus albus (4) Staphylococcus annus (5) Streptococcus hemolyticus (6) Streptococcus vindam (7) Bacillus coli and (8) diphtheroid all failed to produce this typical picture.

The Effects of Over-Dosage with Irradiated Ergosterol. By A. T. SHOHL and (by invitation) HaRry GoldBLatT, Cleveland, Ohio.

Rats were fed normal diets and also ricketogenic diets of both the high calcium and low phosphorus type and high phosphorus and low calcium type. Four mgm. of irradiated ergosterol (Vigantol) were administered daily. They died approximately in seven days. Marked calcification of the blood vessels of the heart, kidneys and stomach was observed and hypercalcification of the epiphyses of the long bones. Calcium and phosphorus of the blood serum and the ash of the fat free bones were determined. Control experiments with unirradiated ergosterol or olive oil showed none of these abnormalities.

Studies on the Value of Acid Neutralization in the Treatment of Gastroduodenal Ulcer. By Joseph A. Capps and (by invitation) Walter Lincoln Palmer, Chicago, Ill.

In this paper a comparison is made between two similar groups of patients, each comprising 27 cases of gastric and duodenal ulcer treated under the same conditions as regards rest and gastric evacuations, with the same diet and with 
hourly feedings of milk and cream. Alkaline powders dissolved in $90 \mathrm{cc}$. of water were administered hourly in one group in doses large enough to neutralize the gastric free acidity as completely as possible throughout the entire digestive period; in the other group, $90 \mathrm{cc}$. of 10 per cent Liebig's beef extract was given every hour in place of the powders, the idea being to stimulate gastric secretion thereby. The duration of spontaneous pain was observed in each group and every fourth day an "acid test" performed for the purpose of ascertaining the duration of sensitivity to this test. The results are based upon this comparison. The alkali group showed a much more prompt cessation of spontaneous pain than did the beef tea group and became acid insensitive more quickly.

\section{A Study of the Reflex Influence of the Colon on the Stomach. By FREd M. SMrth, and (by invitation) George H. MILLER, Iowa City, Iowa.}

There is a considerable difference of opinion relative to the possible reflex influence of the colon on the stomach. Epigastric pain, nausea, and vomiting are frequently associated with chronic colitis. Clinicians and roentgenologists have been inclined to attribute these symptoms to a disturbed motor function of the stomach induced by a reflex stimulation from the colon. The experimental investigation of this problem, however, has led to varying conclusions.

In the present investigation, dogs, anaesthesized by barbital were employed. A mid line incision was made in the upper abdomen which would permit exposure of the stomach and proximal colon. The stomach was filled with warm water and the activity observed during a control period. Croton oil was then introduced into the proximal colon. Precautions were taken to prevent the irritant coming in contact with the ileum. In some instances the bowel was later distended with air. Following the introduction of the irritant into the colon there was usually a marked increase in the activity of the stomach. The peristaltic waves were much more frequent, deeper, and at times very violent. During the height of the increased activity, reverse waves were occasionally noted. The activity of the stomach was often further intensified by distending the colon. In experiments in which the irritation was confined to the appendix, the effect on the stomach was similar. The activity of the stomach induced by the stimulation of the colon or appendix was abolished by atropin.

The Systemic Effect of the Presence of Bile in the Peritoneal Cavity. By G. O. Broun and (by invitation) A. P. BrIGgs, St. Louis, Mo.

Whole bile or solutions of bile salts introduced into the peritoneal cavity give rise to a severe serofibrinous peritonitis. Vomiting and diarrhea occur leading to dehydration. There is a marked fall in blood pressure and extreme prostration and weakness. The heart rate may be slowed in some cases. In others it becomes more rapid. The electrocardiogram shows some irregular changes in the T-waves. Secretion of urine is decreased or completely suppressed.

Changes in blood chemistry are those expected with dehydration and decreased 
urinary output. Blood chlorides show a moderate fall. Non-protein nitrogen and inorganic phosphate are markedly increased. Plasma protein increased slightly. Changes in blood lipoids and blood sugar were irregular and not marked. Tests for the presence of bile salts in the blood stream gave positive reactions. In dogs no increase in blood bilirubin was found although bilirubinuria occurred.

Concentration of the blood is shown by decided increases in red count, cell hematocrit and hemoglobin content. A marked polymorphonuclear leucocytosis occurs. A moderate increase in the fragility of the red corpuscles is observed. Some free hemoglobin may be found in the blood plasma. In the absence of infection, erythrocyte sedimentation rate is delayed. Clotting time is slightly delayed but may remain within normal limits.

The Respiratory Metabolism of the Tubercle Bacillus. ${ }^{1}$ By R. O. LOEBEL, E. SHORR (by invitation) and H. B. Richardson, New York, N. Y.

In the study of tuberculosis it is desirable to know the processes by which the parasite obtains energy and the influence of adverse conditions on its respiratory metabolism.

The following is a study of the oxygen consumption of the tubercle bacillus as influenced (1) by the age of the culture (2) by the constituents of the nutrient medium, and (3) by the $\mathrm{pH}$ of the solution.

After 8 days cultivation on Long's synthetic medium the consumption of oxygen, measured in the micro-respiration apparatus of Warburg, averaged $2.6 \mathrm{cmm}$. per milligram of moist weight, per hour; after 15 days, 2.2; after 22 days, 0.45 ; and after 29 days, practically zero. The maximum was about twice as much as reported for mammalian leucocytes. It was about one-fifth that of a rapidly growing organism of the acid-fast group; i.e., the smegma bacillus.

In order to establish a base-line for the study of nutrients, the organisms were transferred from Long's medium to a similar solution containing only the salts of sodium and potassium. After 6 days the respiration became much reduced, but on retransfer to Long's medium regained nearly its original level. The oxygen consumption in Long's medium could be fractionated as follows:

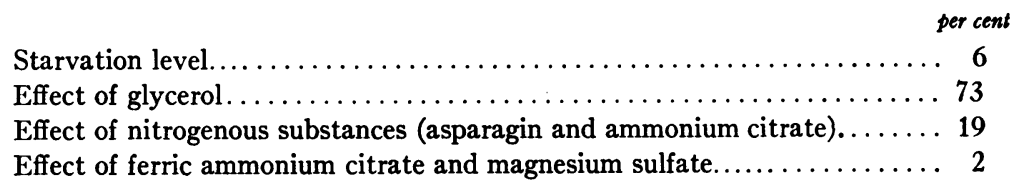

After starvation the organisms retained their original power of growth.

No increase in respiration above the starvation level was observed as the result of transfer from buffered saline to a similar solution containing 5 per cent glucose

${ }^{1}$ Aided by a grant from the Research Committee of the National Research Association. 
or levulose. This is in accord with the well known difficulty of cultivating the organisms by the use of sugars. Sodium lactate caused a rise which even exceeded the effect of glycerol, but was entirely ineffective as a substitute for glycerol in the promotion of growth. This is an instance in which the energy metabolism is dissociated from growth.

TABLE 1

The influonce of foodstuffs on the growth and respiration of the tubercle bacillus-H 37

\begin{tabular}{|c|c|c|c|c|c|c|}
\hline \multirow{2}{*}{ Duration } & \multicolumn{5}{|c|}{ Oxygen consumption per moist milligram } & \multirow{2}{*}{ Remarks } \\
\hline & $\begin{array}{c}\text { No } \\
\text { foodstuff }\end{array}$ & $\begin{array}{c}\text { Glycerol } \\
5 \text { per cent }\end{array}$ & $\begin{array}{l}\text { Na lactate } \\
5 \text { per cent }\end{array}$ & $\begin{array}{c}\text { Glucose } \\
5 \text { per cent }\end{array}$ & $\begin{array}{c}\text { Levulose } \\
5 \text { per cent }\end{array}$ & \\
\hline hours & c. $m m$. & c. $m m$. & c. $m m$. & c. $m m$. & c. $m m$. & \\
\hline 1 & 1.1 & 1.8 & 2.1 & 1.3 & 1.2 & $\begin{array}{l}16 \text { d. culture } \\
2 \text { d. starvation }\end{array}$ \\
\hline 1 & 0.6 & 1.5 & 2.4 & 0.9 & 0.5 & $\begin{array}{l}16 \mathrm{~d} \text {. culture } \\
2 \mathrm{~d} \text {. starvation }\end{array}$ \\
\hline 1 & 1.0 & 1.2 & 1.6 & 0.9 & 0.7 & \multirow{4}{*}{$\begin{array}{l}15 \mathrm{~d} \text {. culture } \\
2 \mathrm{~d} \text {. starvation }\end{array}$} \\
\hline \multirow[t]{3}{*}{2} & 1.8 & 2.4 & 3.3 & 1.8 & 1.5 & \\
\hline & \multicolumn{5}{|c|}{ Growth on a modified Long's medium* } & \\
\hline & None & Profuse & None & Slight & None & \\
\hline
\end{tabular}

* The foodstuff at the head of the column was substituted for the glycerol of Long's medium.

In saline solutions buffered with phosphate mixtures the oxygen consumption for short periods was much the same over a range extending from $\mathrm{pH} 1.5$ to 12.0 .

TABLE 2

The influence of hydrogen ion concentration on respiration of the tubercle bacillus-H 37

\begin{tabular}{|c|c|c|c|c|c|c|}
\hline \multirow{2}{*}{ Duration } & \multicolumn{5}{|c|}{ Oxygen consumption per moist milligram } & \multirow{2}{*}{$\begin{array}{l}\text { Remarks-phosphate } \\
\text { buffers } \mathbf{M} / 150\end{array}$} \\
\hline & $\mathrm{pH} 1.5$ & $\mathrm{pH} 5.6$ & $\mathrm{pH} 7.4$ & $\mathrm{pH} 8.8$ & pH 12.0 & \\
\hline hours & c. $m m$. & c. $m m$. & c. $m m$. & c. $m m$. & c. $m m$. & \\
\hline 1 & 1.0 & 1.0 & 1.1 & 1.1 & 1.2 & $\begin{array}{l}16 \mathrm{~d} . \text { culture } \\
3 \mathrm{~d} \text {. starvation }\end{array}$ \\
\hline 1 & 1.3 & 1.6 & 1.6 & 1.4 & 1.5 & $10 \mathrm{~d}$. culture \\
\hline 2 & 2.3 & 3.3 & 2.8 & 2.6 & 2.8 & \\
\hline 3 & 3.3 & 5.1 & 4.4 & 4.0 & 4.3 & \\
\hline 1 & & 1.7 & 1.8 & $1.5^{\circ}$ & & $10 \mathrm{~d}$. culture \\
\hline
\end{tabular}


The Chemical Metabolism of Normal and Diseased Lymph Nodes. By Henry Jackson, Jr., and (by invitation) Frederic Parker Jr., and E. C. Glover, Boston, Mass.

For years there has been much discussion as to the nature of those diseases which may be classified under the general heading malignant lymphoma or lymphoblastoma. Some pathologists hold that they are true malignant processes, while others maintain that they are infectious or granulomatous in nature. Warburg has shown that with certain exceptions malignant disease tissue has a characteristic metabolism. In brief, neoplasms use but little oxygen but consume large quantities of sugar under both aerobic and anaerobic conditions; whereas normal organs destroy but little sugar either in the presence or absence of oxygen and embryonic material destroys but little sugar under aerobic but large amounts under anaerobic conditions.

We have examined the metabolism of twenty-two malignant lymphomas and compared these with the metabolism of normal and tuberculous nodes and with nodes containing metastatic malignancy. We have also included determinations on several benign tumors.

Our findings may be summarized as follows:

Average glycolysis

(Milligrams per milligram hour)

\begin{tabular}{|c|c|c|}
\hline & Aerobic & Anaerobic \\
\hline Normal nodes. . & 0.020 & 0.035 \\
\hline Lymphomata... & 0.050 & 0.075 \\
\hline Tuberculosis... & 0.075 & 0.106 \\
\hline Carcinoma......... & 0.110 & 0.134 \\
\hline
\end{tabular}

Extremes of glycolysis

(Milligrams per milligram hour)

\begin{tabular}{|c|c|c|}
\hline & Aerobic & Anaterobic \\
\hline Normal nodes. . . & $0.00-0.05$ & $0.01-0.075$ \\
\hline Lymphomata....... & $0.02-0.10$ & $0.04-0.140$ \\
\hline Tuberculosis ...... & $0.05-0.13$ & $0.08-0.19$ \\
\hline 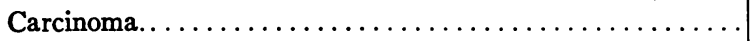 & $0.07-0.17$ & $0.09-0.23$ \\
\hline
\end{tabular}

In order to overcome certain exceptions and difficulties Warburg introduced a value "U" which was the anaerobic glycolysis less twice the oxygen consumption. This value he found to be negative for normal, zero for embryonic and a high positive for cancerous tissues. 
Calculating this figure from our data we find:

Value for " $U$ "

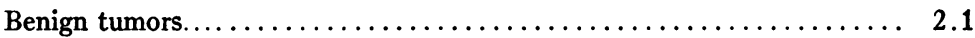

Normal nodes. . . . . . . . . . . . . . . . . . . . . . . . . 4.3

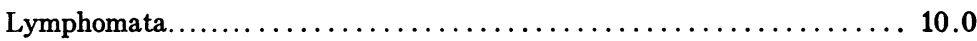

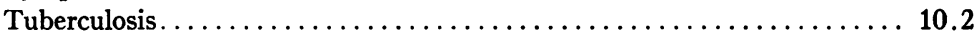

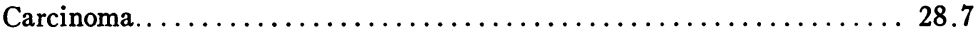

It is difficult to draw definite conclusions from these data at the present time. More work is being done and the data elaborated. For the present we would point out:

1. There is considerable overlapping of the various classifications. By metabolic figures alone the tissue cannot be surely classified. The value $U$ is more consistent.

2. From the value $U$ one would place the malignant lymphomata among the granulomatous rather than the neoplastic diseases.

3. Further study is being made of the relation of the metabolic changes to the particular cell involved.

The Effect of Iron on Blood Formation as Influenced by Changing the Acidity of the Gastric Contents in Certain Cases of Anemia. By Stacy R. Mettrer, (by invitation) and GeORGe R. MrNot, Boston, Mass.

The oral administration of iron produces in certain cases of "secondary" anemia a response of the reticulocytes. The anemia in the 4 cases reported upon was associated with defective diets and disorders of digestion or chronic blood loss. In these cases when the gastric contents was made neutral in reaction, the feeding of a given daily amount ( 0.08 to $0.32 \mathrm{gram})$ of iron produced a response of reticulocytes. Soon afterwards, however, when the same dose of iron was maintained, a second and greater response of these cells occurred after the gastric contents was rendered acid.

In the same case two distinct responses of the reticulocytes within a short period of time may be interpreted to indicate that the cause of the second response is more potent than that producing the first. Furthermore, during a third period when the amount of iron was increased four fold or more in these cases, there developed a third response of the reticulocytes. This indicated that iron was the essential factor in producing the response, modified by changes in the acidity of the gastric contents, and is distinct evidence that large doses of iron may be much more effective than relatively small ones. The patients with great rapidity increased to normal the concentration of their hemoglobin and red blood corpuscles.

Urobilinogen Excretion in Addison's "Pernicious" Anemia Before and After Liver Therapy. By Duncan Graham and (by invitation) RaY FarquHarson, Henry Borsook, AND A. M. Goulding, Toronto.

In Addison's "pernicious" anemia in state of relapse with anemia the urobilino- 
gen excretion is greatly increased and may be several times the normal value. This is usually associated with a high bilirubin content of the blood plasma. Following liver therapy and beginning about the peak of the reticulocyte response there is always a sharp decrease in urobilinogen excretion which falls in a few days to a point within normal limits. In severe cases the amount of urobilinogen excreted per day is equivalent to 9 to 12 grams of hemoglobin and in one case it amounted to one-eighth of the total blood hemoglobin of the body.

In some cases of Addison's "pernicious" anemia showing little anemia but presenting other manifestation of the disease, such as subacute combined degeneration of the cord, the blood bilirubin is usually normal but the urobilinogen excretion is increased somewhat above a high normal value. On liver therapy such cases show a low reticulocyte response and the urobilinogen excretion falls slowly and gradually to within normal limits.

These observations on urobilinogen excretion in cases of Addison's "pernicious" anemia go to show: (1) that in the state of relapse there is a markedly increased blood destruction; (2) that adequate liver treatment controls this destruction; (3) that the rapid fall in urobilinogen excretion, beginning during the reticulocyte response, suggests that the abnormal red blood corpuscles present in a relapse are the ones chiefly affected in the stage of increased blood destruction.

Some Effects of Adrenalin on the Heart with Especial Reference to Its Use As a Test for Angina Pectoris. By S. A. Levine, and (by invitation) A. C. ERNSTENe, and B. M. JACobson, Boston, Mass.

Observations by one of us (S. A. L.) on a patient with bronchial asthma and angina pectoris in whom an attack of angina was precipitated by a therapeutic dose of epinephrine gave rise to the idea that possibly epinephrine could be employed as a diagnostic measure in patients in whom the diagnosis of angina pectoris was not certain. With this in mind, one cubic centimeter doses of a 1:1000 solution of epinephrine chloride have been given subcutaneously to eleven patients with angina pectoris, and in all but one a typical anginal attack has been produced. The single exception cannot, for various reasons, be accepted as a complete failure. In some instances the pain was allowed to subside spontaneously, while in others it was brought to an end by nitroglycerine or amyl nitrite. Ten patients of the same age group as those with angina pectoris but without evidence of cardiac disease and ten normal young adults have been tested similarly, and in no instance has anginal pain been produced.

Frequent blood pressure determinations and electrocardiograms were taken in each experiment. It was originally hoped that distinctive changes might be found in the electrocardiograms of anginal patients as a result of the epinephrine, which might further serve as a diagnostic aid. In only one case, however, did any important changes develop, although extrasystoles were frequently noted. There was nevertheless a striking difference in the response of the $T$-wave in the three 
groups. In the patients with angina pectoris, the $\mathrm{T}$-wave invariably increased in amplitude; while in the group of older controls there was, as a rule, very little change in amplitude, and in the young controls there was usually a decided diminution in height of the $\mathrm{T}$-wave. This work indicates that adrenalin may serve as a diagnostic test for angina pectoris. Its use, however, would need to be applied with caution and discretion.

Emphysema Simulating Cardiac Decompensation. By W. B. Kountz (by invitation) and H. L. Alexander, St. Louis, Mo.

Sixty-three cases of advanced emphysema were studied. In all, there were dyspnea on exertion, and some cyanosis; and in forty, dependent edema. Direct examination of the cardiovascular system showed no abnormality excepting consistently increased venous pressure.

Autopsies were performed in nine cases. Eight of these had had dependent edema. No cardiac lesions appeared. The right ventricular wall was not increased either in thickness or in weight.

Dyspnea in these cases is attributed to the consistently lowered vital capacity; cyanosis, to deficient pulmonary ventilation. The dependent edema is presumed to be caused mainly by increased venous pressure.

The rise in venous pressure in these cases was studied experimentally, and found to be due to two factors; increased intrathoracic pressure and anoxemia.

An extensive emphysema in dogs was produced by inserting an adjustable ballvalve in the trachea. During the development of the emphysema, periodic intrathoracic and peripheral venous pressures were taken simultaneously. It was found that the venous pressure rises proportionately to the increase in intrathoracic pressure. Dogs were rendered partially anoxemic and a rise in venous pressure in proportion to the degree of the oxygen unsaturation of the arterial blood was observed.

These observations tend to refute persistent statements that emphysema leads to right heart failure.

Chronic Infectious Non-Tuberculous Pulmonary Lesions of Childhood and Their

Relation to Bronchiectasis. By F. Maurice McPhedran, Philadelphia, Pa.

A number of these lesions have been observed in children during the past six years. Some were seen shortly after an illness severe enough to initiate a lesion, many during recurring attacks of pneumonia from which a persisting infiltration results; others, without symptoms, were discovered by routine $x$-ray examination. The last usually sooner or later suffer characteristic bronchopneumonic exacerbations, which are roentgenographically recordable, sometimes producing severe illness, sometimes accompanying apparently trivial coryza.

The lesions predominate in the left lower lobe. When early, whether right or left, they are densest close to the heart. Synchronized diastolic roentgenograms accurately record slight lesions and eliminate misleading blurring due to systole. 
Early diagnosis and care is important to prevent advanced scarring and bronchiectasis.

Among 106 colored children occurred five cases, among 325 Italians 19, among 341 other white children only 4 . Five cases occurred in one family, three in each of two others. In two additional families each presenting two cases the fathers had suffered from clinical sinusitis for many years.

These lesions are commonly diagnosed tuberculosis. Differentiation presents few difficulties.

No characteristic or predominating organism has been found. Paranasal sinusitis is common.

Clinical and Experimental Studies of the Effect of Ergotamine on Metabolism and the Circulation. By JoHn B. Youmans, M.D., and (by invitation) W. H. TRIMBLE.

Ergotamine tartrate in doses of $0.5 \mathrm{mgm}$. subcutaneously caused a small drop in pulse rate and a small rise in diastolic pressure in normal human subjects under basal conditions. No significant effect on metabolic rate or blood sugar was noticed over periods up to three hours. Severe muscle pains and soreness, nausea, headache and lassitude were common. Atropine in doses of $1.2 \mathrm{mgm}$. subcutaneously prevented or abolished the drop in pulse rate. Continued administration of ergotamine in doses of $1 \mathrm{mgm}$. by mouth, three times daily for a week had no significant effect on metabolic rate. Patients with thyrotoxicosis showed in general similar results but the effect on pulse rate and blood pressure was much more marked.

Doses somewhat larger ( 0.105 to $0.5 \mathrm{mgm}$. per animal), but smaller than those usually reported, were employed intravenously in trained unnarcotized dogs. In these animals under basal conditions ergotamine caused an immediate and marked fall in heart rate, which was prevented or abolished by atropine. No constant changes in oxygen consumption or blood sugar levels were observed over periods up to three hours. In the doses used ergotamine failed to prevent or diminish epinephrine hyperglycemia in these animals.

Observations on Changes in Respiration and Circulation Occurring Coincidentally with Sensations of Faintness and Impending Syncope in Normal Individuals. By IsaAc Starr, JR., and (by invitation) Leon H. Collins, Jr., Philadelphia, $\mathrm{Pa}$.

While there has been much speculation concerning the physiology of syncope (Gowers, Hering, etc.), observations upon this condition have been limited to changes in pulse rate and blood pressure, chiefly after collapse (Cotton and Lewis). The opportunity to extend these observations came during experiments designed to determine the applicability of the ethyl iodide cardiac output method (Starr and Gamble) to the problem of the effect of posture on blood flow. The subjects, standing, inhaled ethyl iodide, blood being obtained from a vein on the back of 
one hand immersed in water at $45^{\circ} \mathrm{C}$. A graphic record of respiration was taken from the spirometer, blood pressure and pulse rates were observed at frequent intervals.

Four subjects experienced faintness and two collapsed. The records show that the sensation of faintness was always accompanied by hyperventilation but was usually without significant change of pulse rate, blood pressure or cardiac output. Symptoms of collapse were preceded by marked hyperventilation and accompanied by marked fall in pulse rate and blood pressure and apparent diminution of ventilation. Alveolar $\mathrm{CO}_{2}$ was very low in two such cases; in one of which improvement followed rebreathing. The cardiac output could not be determined at the time of collapse; it remained unchanged or fell but little during the period preceding.

Certain features of the physiological picture described: low blood pressure without diminution of cardiac output have been produced in anesthetized cats (Dale and Evans) by hyperventilation by blowing off of $\mathrm{CO}_{2}$, but no pronounced fall of heart rate occurred in these experiments. Other features, hyperventilation and slow pulse regularly occur directly after the production of cerebral anemia in animals (L. Hill, Pike, Schmidt, etc.), but a high rise of blood pressure usually occurred at this time. In an occasional experiment in this laboratory, occlusion of the cerebral arteries of an anesthetized cat caused prolonged hyperventilation and an elevation of blood pressure lasting only a few seconds followed by marked slowing of the pulse rate with fall of blood pressure below the initial level. These results seem essentially similar to the physiological picture we observed in impending syncope in normal individuals.

The fact that the hyperventilation precedes the fall of blood pressure and pulse rate in our subjects is evidence against the conception (Lewis) that the primary cause of syncope is reflex vagus stimulation. Our observations are consistent with the conception that syncope is caused by cerebral anemia secondary to failure of the peripheral circulation to adjust itself to the upright position and so maintain the blood supply to the brain.

Skin Reactions of Patients and Normal Individuals to Protein Extracts of Streptococci. By Clifford L. Derick and (by invitation) Marshall N. Fulton, Boston, Mass.

Skin tests were carried out on 366 general hospital patients, 67 infants and children in a general medical ward and 51 patients with rheumatic fever or chorea in whom the disease was either active or early in the convalescent stage. A group of apparently normal adults were similarly tested for comparison.

The purpose was to determine what proportion of these individuals would show skin sensitiveness of the tuberculin type to protein extracts of different varieties of streptococci. Test materials used were pure nitrogen-constant extracts from each of three types of streptococci-hemolytic, green-producing, and indifferent. A similarly prepared extract from Baker's yeast was used for control purposes. Varying amounts in normal saline solution were injected into the skin of the forearm. All readings were made at 24-hour intervals for 2 or more days. 
The analyzed results reveal that patients with certain diseases show a high incidence of positive reactions; that there seems to be a relationship between previous infections and skin sensitiveness; and that age, except in the very young, plays a minor if any rôle.

The presence of reaction is looked upon as indicating present or previous infection with streptococci and is not characteristic of any one disease.

\section{Rate of Removal of Bacteria from the Blood in Human Disease. By REUBEN} Ottenberg, New York, N. Y.

A technic has been developed by which simultaneous blood cultures are made from the two internal jugular veins. In sinus thrombosis there is usually a much larger number of colonies in one vein than in the other. In 20 of the more recent cases a simultaneous blood culture was also made from an arm vein. I wish at present to point out the very small number of colonies usually found in the arm vein as compared with that jugular vein which is draining the lesion most directly.

Among 17 cases of otitic infections suspected to be sinus thrombosis there were 7 in which the colonies could be counted. In every one of these the number of colonies in the arm blood was much smaller than in one or both jugulars. Thus:

Colonies per cubic centimeter of blood

\begin{tabular}{l|c|c|c|l}
\hline & $\begin{array}{c}\text { Right } \\
\text { jugular }\end{array}$ & $\begin{array}{c}\text { Left } \\
\text { jugular }\end{array}$ & Arm vein & \\
\cline { 2 - 3 } Case $4 \ldots \ldots \ldots \ldots \ldots \ldots$ & 122 & 7 & 6 & Left sinus thrombosis \\
Case $25 \ldots \ldots \ldots \ldots \ldots \ldots$ & 600 & 11 & 1 & Right sinus thrombosis \\
Case $32 \ldots \ldots \ldots \ldots \ldots \ldots$ & 250 & 240 & $1 / 3$ & Right sinus thrombosis \\
\hline
\end{tabular}

In two cases of ulcerative endocarditis the number of colonies found in the jugular veins and arm vein were approximately equal.

It is evident then that during circulation of blood through the lungs an enormous number of bacteria are removed. The number in the periphery represents only a small fraction of those which are constantly being fed into the blood stream.

White Blood Cells in Medical Conditions. By Paul Reznikofr, New York, N. Y.

The object of this study was to determine variations of the white blood cells and the intensity and course of "the shift to the left" (the response of young polymorphonuclear cells) during the course of illness. Total white cell and Schilling counts were performed on 177 patients on the medical wards.

These included 78 patients suffering from pneumonia and 23 having some form of upper respiratory infection. Four tabulations were made: $(a)$ total white cell counts, $(b)$ percentage of polymorphonuclears $(c)$ percentage of all cells which are young polymorphonuclears, $(d)$ percentage of all polymorphonuclears which are young.

It was found that all patients suffering from acute infections have a shift to the 
left regardless of their total white blood, total polymorphonuclear count or temperature. The increase in the relative and absolute number of young polymorphonuclears varies roughly with the intensity of the infection. The return of the shift to the right or failure to do so is the most accurate gauge of prognosis that can be obtained from blood studies.

Arthritic Pain in Relation to the Weather. By L. G. RownTREe and (by invitation) E. B. Rentschler and F. R. VAN ZANT, Rochester, Minn.

For a period of a year we have studied the pain in a series of arthritic patients, 377 in all. We have found a striking relationship between the pain and the presence of storms about 90 per cent of the time. Between barometric pressure and pain we have found a relationship 93 per cent of the time., In 72 per cent there has been a direct relationship, and in 21 per cent a negative, or inverse relationship. Sunshine seems to be another factor of considerable interest. We have also studied a group of arthritic "weather prophets" and found that many of them can predict weather changes 12 to 24 hours in advance. The literature has been covered in connection with this subject, but little of an exact nature has been written to date. The possible relationship of the sympathetic nervous system to this phenomenon has been introduced through the discussion of a patient in whom removal of the second, third and fourth lumbar sympathetics was done. This patient was suffering from arthritis and had always noticed a relationship between storms and increase of her pain. After the operation there was no such relationship in the lower extremities, while the upper extremities, which were also afflicted with arthritis, continued to be affected by storms.

The Respiratory Quotient of the Obese During Reduction. By H. B. McClugGage, and J. M. Strang, (by invitation) and Frank A. Evans, Pittsburgh, Pa.

Observations made on ten obese patients undergoing reduction by dieting during an average period of fourteen weeks showed a basal R.Q. of less than 0.707 in 35 per cent of 112 determinations. The average R.Q. before dieting was 0.776 for 8 subjects, the average R.Q. during the dieting period was 0.728 . Very low respiratory quotients appeared usually after two weeks of dieting. Only one patient failed to go below 0.707 at some time. The average respiratory quotient reaches its lowest level during the third month when 19 determinations on 7 patients averaged 0.701 .

The lowest observed R.Q. 0.632, was obtained at the eighth test on a patient on whom 6 of 13 tests ran low. Another patient, on whom 13 of 26 determinations were low, had values of $0.653,0.650$ and 0.657 on three successive weeks and a minimum of 0.640 . The average of the lowest respiratory quotients observed on 9 patients was 0.661 .

These very low respiratory quotients do not correspond to: (1) the periods of most rapid weight loss; or (2) the presence or absence of acetone bodies in the urine. A large number of blood $\mathrm{CO}_{2}$ combining power determinations have fallen within normal limits. 
Observations Concerning Intracranial Circulation in the Human Subject. By William G. Lennox, Boston, Mass.

The oxygen and carbon dioxide content of arterial blood and of venous blood from the internal and external jugular and the basilic veins was measured in a number of patients. In these subjects, the gaseous content of blood from the external jugular vein approached that of arterial blood. In many of the individuals there was a wide discrepancy between the gaseous content of blood from the internal jugular and the basilic veins. The average measurements for the whole group, however, were about the same.

In experiments conducted with Dr. Soma Weiss, it was observed that the intravenous injection of histamine caused the venous blood from each of these three veins to become more arterial-like. Apparently cerebral vessels respond to such stimulation in much the same way as vessels of the skin.

The Cerebral Circulation. $X$. The Action of Histamine. By H. S. Forbes, and H. G. WolfF, (by invitation) and Stanley CoBb, Boston, Mass.

By the method developed by one of us for observing the pial vessels through a window in the skull, studies have been made of the effect of histamine on the cerebral circulation. It was observed that the vessels of the brain react to intravenous injection of histamine in a very different manner, depending on whether the animal is under ether or amytal anesthesia. Under ether the vessels of the brain are already dilated and so do not dilate to any extent, if at all, following intravenous injection of histamine. On the contrary they often become narrower and the cerebrospinal fluid pressure falls.

Local application of histamine to the surface of the brain always results in dilatation of the pial vessels, without noticeably affecting intracranial or systemic vascular pressures. Intravenous injection of histamine (in animal's under amytal) causes great pial artery dilatation in spite of a coincident fall in systemic arterial pressure.

Studies in the Etiology and Iodine Reactions of Simple Goiter in Rabbits. By Bruce Webster, (by invitation) and Alan M. Chesney, Baltimore, Md.

Further studies have been carried out to determine the etiology of an epidemic of simple goiter in rabbits. These suggest that the basic factor in this instance is a dietary one. The addition of $7.5 \mathrm{mgm}$. of iodine per week to the goiter producing diet has been found sufficient to prevent the development of goiter. Improving the sanitary conditions under which the animals were kept, by altering the manner of caging so as to reduce the fecal contamination of the food, was found to exert only slight protective action against the goiter-producing influence.

Previous studies have shown that the administration of iodine to goitrous rabbits is followed by a marked increase in heat production. Studies have been made in an effort to quantitate the production of thyroid hormone against available iodine. Rises in heat production were studied after the administration of 
single small doses of potassium iodide to animals in which the degree of hyperplasia of the thyroid gland had been previously determined by biopsy. The increase in heat production appeared to vary directly with the amount of iodine exhibited, as did also the extent of involution of the gland. This relationship apparently held true until involution was complete.

The Effect of Liver and of Liver Extract upon Appetite. By A. C. CURTIS (by invitation) and L. H. NewBURgh, Ann Arbor, Mich.

The addition of 2 per cent protein as dried ether extracted liver to a basic rat diet containing 2 per cent vitamine B powder (Harris) causes greater energy ingestion and better growth than does the addition to this diet of 2 per cent protein in the form of casein.

If vitamine B powder is omitted from both diets, greater loss of appetite and weight occurs in the group of rats eating the basic diet containing 2 per cent protein in the form of casein. All animals of both groups develop polyneuritis.

The addition of 2 per cent liver extract (Lilly) to the basic rat diet plus one yeast vitamine powder tablet daily (Harris) causes much greater ingestion of energy and much better growth than was observed when 2 per cent dried ether extracted liver protein or casein protein was added to the basic rat diet.

When the basic diet, containing added liver extract (Lilly), ether extracted liver protein, or casein protein, is supplemented by sufficient yeast vitamine powder (Harris), energy ingestion and growth are equal.

If basic rat diets, containing autoclaved ether extracted liver and liver extract, are fed without yeast vitamine powder, polyneuritis develops in all experimental animals.

When 2 per cent liver extract (Lilly) is added to the basic diet, which contains no other source of vitamine $B$, growth and energy ingestion are approximately normal. The replacement of liver extract by equal amounts of yeast vitamine powder (Harris) causes less growth and less energy ingestion.

A patient with pernicious anemia was fed 24 grams of autoclaved liver extract (Lilly) daily for 6 days and did not experience a rise in reticulated cells or red cells. At the end of this period 24 grams of unaltered liver extract (Lilly) was fed daily with a reticulated cell rise and red cell rise occurring in the usual time.

1. The factor in liver that effects appetite is, seemingly, that fraction of vitamine B.

2. Liver extract (Lilly) appears to contain the appetite factor of vitamine B in concentrated form.

Auricular Fibrillation in Graves' Disease: By PaUl S. BARKer, and AnN BohnING (by invitation) and Franx N. WILson, Ann Arbor, Mich.

A study of 107 unselected cases of auricular fibrillation due to Graves' disease, and observed from 1923 to 1927 , leads to the following conclusions:

The auricular fibrillation due to Graves' disease is more likely to be transient 
or paroxysmal than that due to other causes. One fourth of the cases in this series were of this type.

The cardiac manifestations of Graves' disease may dominate the picture and obscure the underlying thyroid disorder; they may even antedate all other recognizable signs of the Graves' disease causing them.

Digitalis is less effective than in fibrillation not due to Graves' disease. The amounts tolerated are larger, and the beneficial effects are less striking.

Following successful treatment of the underlying Graves' disease, recovery from fibrillation is usually prompt and striking. Restitution of the heart to normal is often complete. Quinidine is often very useful in restoring permanent normal rhythm.

Cardiac hypertrophy is seldom pronounced. Enlargement, when present, is due chiefly to dilatation.

In some respects the cardiac disturbances of Graves' disease resemble those of toxemia of acute infection.

Although it is difficult to estimate the relative importance of mechanical and toxic factors, the infrequency of hypertrophy and the character of the disturbances suggest that the latter is of major importance.

A Comparison of the Coronary and Digitalis T-Waves. An Electrocardiographic Study. By Walter W. Hamburger, Chicago, Ill.

Inversion of the $\mathrm{T}$-wave of the human electrocardiogram, is one of the most frequent findings in clinical electrocardiography. The two most frequent causes of $\mathrm{T}$-wave inversion are coronary disease and digitalization. The character of inversion is different in these two conditions: coronary inversion shows the typical cove shape (Pardee): digitalis inversion appears as an immediate straight line depression of the R-T interval. A coronary-digitalis wave appears as a merging of the two. Examples of these three types of inversion are presented. The clinical importance of recognition of these various types is emphasized.

Skin Tests with Pneumococcus and B. influenzae Antigens in Influenza and Pneumonia. By Allan K. Poole, and John H. Bumstead, (by invitation) and Francis G. Blake, New Haven, Conn.

The study was undertaken with the purpose of determining the skin reactivity or allergy of patients with uncomplicated influenza and with pneumonia to antigens prepared from Pneumococcus Type I, Pneumococcus Type II and B. influenzae. Patients with influenza (23 cases) consistently showed marked reactivity to all three antigens in the acute febrile stage, lessened reactivity during the first week of convalescence and in the majority no reactivity after the 20th day. Patients with pneumonia (32 cases) showed a striking contrast. With one exception, a case of streptococcus pneumonia, no case reacted to the pneumococcus antigens during the acute stage, but those retested became reactive during convalescence. Forty per cent reacted to $B$. influenzae antigen during the acute 
stage. Those retested in convalescence retained or developed reactivity. In brief, patients with influenza appear to show heightened reactivity to bacterial antigens during the acute stage and tend to lose this after recovery, patients with pneumonia show little reactivity during the acute stage and tend to become more reactive after recovery. The interpretation awaits further studies now being carried on.

Venous Pressure in General Anaesthesia. By O. O. Meyer (by invitation) and

Wm. S. Middleton, Madison, Wis.

Forty-two individuals under general anaesthesia have been studied with a view to determining the infuence of such agents. The results may be summarized as follows:

1. Coincident with the increased muscular effort and altered respiratory function of the induction period, pronounced increases in venous pressure are noted.

2. Thereafter a subsidence occurs to a plateau of venous pressure somewhat elevated above the normal, which is maintained throughout the maintenance of anaesthesia.

3. Alterations in this plateau apparently depend upon reflex stimuli, usually in a period of lightened anaesthesia.

4. Elevations in venous pressure occur on release from anaesthesia dependent upon such acts as retching, vomiting, etc.

5. Carbon dioxide inhalations operate apparently independently to increase venous pressure.

These results are not interpreted as bearing a causal relation to the circulatory accidents of general anaesthesia and surgical operation. Indeed, the demands of ordinary life with its occasional calls for sharp elevation in venous pressure, as in the act of defecation, may lead to much greater strain on the right heart than has been noted in these venous pressure determinations under properly administered general anaesthetics.

\section{Red Blood Cell Measurements in the Diagnosis of Metastatic Cancer in the Bone} Marrow. By RaphaEl IsaAcs and (by invitation) MAdElaINe R. Brown, Ann Arbor, Mich.

In patients with carcinoma with metastasis to the bone marrow, red blood cells smaller or larger than normal appear in greater frequency in the blood stream than in normal persons. Seven out of thirteen patients showed a disproportionate percentage of cells larger than normal and all of them showed a relative increase in the percentage of cells smaller than normal at some stage in their disease. In no case did the degree of microcytosis approach that of the blood after hemorrhage or in sezondary anemia from other cause. With the present data no evident correlation between the degree of variation in the size of the cells and the extent of the metastasis, can be made, due, probably, to the difficulty in judging the true degree of the marrow involvement. The presence of a relatively 
higher percentage than normal of abnormal sized red blood cells in the peripheral blood of patients having carcinoma of the breast or prostate, and with a normal blood count suggests the possibility of bone marrow metastasis. Anemia from other causes must be eliminated when the red blood cell count is lower than normal before the abnormal sized cells can be considered as suggestive of bone metastasis, although cells larger than normal are of greater significance.

\section{A Comparison of Volume Index and Diameter of the Red Cells in Different Types of Anemia. By Russell L. HAden, Kansas City, Kans.}

Accurate knowledge of the size of the red cells is of fundamental importance in the study of the anemias. The size of the average cell may be determined from the volume index which gives the volume of the average cell. The size may also be determined by measuring the diameter of a representative group of cells. Fifty.cases each of pernicious anemia and of secondary anemia have been studied by these two methods. The data obtained and the advantages and disadvantages of the two methods are discussed.

The Measurement of Temperatures in the Bladder, Cervix and Rectum of Patients Receiving Diathermy Treatment of the Pelvis. By F. W. BISHOP and E. K. RITCHIE, (by invitation) and S. L. WARREN, Rochester, N. Y.

The pelvis was treated by passing a high frequency or diathermy current between a speculum in the vagina and a sacral plate.

Temperatures were measured by thermocouples placed in the cervix, bladder, rectum and elsewhere.

When the high frequency is turned on, all of the regions measured showed a simultaneous rise in temperature to a plateau which was maintained while the current was applied. On turning off the current there was a similar drop in the temperatures to the original value. Each state of equilibrium was reached in about five minutes.

With currents of from 1800 to 2400 milliamperes in average patients, local temperatures as high as $44^{\circ} \mathrm{C}$, were measured and maintained at this level during treatment. The temperatures in the rectum, cervix and bladder were very nearly the same. Individual patients varied considerably in the amount of increase in temperature found, the average attained being around $42^{\circ} \mathrm{C}$. Body temperature (mouth) was elevated only $0.5^{\circ}$ to $1.0^{\circ} \mathrm{C}$. Blood pressure was unaffected.

The Question of Arsphenamine-Resistant Syphilis. By JOSEPH EARLE MOORE, and (by invitation) HARRY M. RoBInson, Baltimore, Md.

A survey of the literature indicates that in Germany and perhaps elsewhere in Europe, early syphilis reacts to arsphenamine treatment less favorably now than in the years before the War, in the sense that secondary relapses are more frequent, the blood Wassermann is not so rapidly reduced to negative, and an increasing number of patients whose lesions fail to heal under arsphenamine treatment are 
appearing. It seems probable that this situation is due less to any decrease in the therapeutic activity of arsphenamine, or to the development of so-called arsphenamine-fast strains of spirochetes, than to the reaction of the individual patient to treatment. Composite Wassermann curves of 1116 patients with early syphilis studied from 1914 to 1927 in the Syphilis Clinic of the Johns Hopkins Hospital show that there is no significant difference in serologic results in recent as compared with earlier years. Relapses of a secondary type are, in our material, no more frequent in 1925-1927 than in 1914-1923. True arsphenamine-resistant syphilis is not increasing in this locality. Patients with lessened resistance to syphilitic infection as measured by the standards of "seronegative early secondary syphilis" or "premature Wassermann negativity" are no more frequent in our material now than in earlier years. There is no evidence to indicate that, in this part of the United States, arsphenamine is less efficacious than formerly in the treatment of syphilis; or that arsphenamine resistant syphilis is increasing. Certain general aspects of the phenomenon of arsphenamine-resistance are discussed.

The Relation of Recovery and Development of Humoral Immunity in Pneumococcus Pneumonia in Children. By C. O'Donovan, JR., (by invitation) and JAMES D. Trask, New Haven, Conn.

In fixed type pneumococcus pneumonia in adults recovery has been shown to be associated with the development of type specific humoral antibodies.

Children are supposed to recover from this disease more regularly than adults. Accordingly a study was made of the development of type specific agglutinins in the blood serum of 19 children with the disease. There were 12 Type I, 2 Type II and 5 Type III cases; all recovered. However the development of specific antibodies was found to be significantly less marked than has been reported for adults.

The Tissue Transfer Method of Determining Cure of Syphilis in Man. By Hugh J. Morgan and (by invitation) James L. Alloway, Nashville, Tenn.

Brown and Pearce have demonstrated the frequency with which treponemas localize in the lymph nodes of infected rabbits and remain there long after the acute stage of the infection has passed. This lymph node reservoir for treponemas is used by workers in experimental syphilis as a means for recovering organisms from animals without active lesions. This may be readily done by emulsifying a lymph node and injecting it into the testicle of a normal rabbit. An acute orchitis develops in the inoculated animal or in subsequent transfers. After treatment of experimental syphilis in the rabbit, failure to recover organisms by this method has been interpreted as an indication of cure.

In 1927 Chesney and Kemp stimulated interest in the possibility that the tissue transfer method of determining cure of experimental syphilitic infection might be applicable to syphilis in man. They applied the method to three patients and 
were unable to recover treponemas from lymph nodes after suitable treatment. This work raised the very important question as to whether or not these negative results indicate biological cure.

In order to throw some light on this subject we have undertaken a study of the recoverability of treponemas from lymph nodes of untreated patients in different stages of the disease. It was felt that if, in untreated cases of syphilis, as in the experimental disease, treponemas could always be recovered from lymph nodes, then the positive or negative findings after treatment would be of great significance and might be used as criteria of cure.

In all instances enlarged lymph nodes (inguinal, epitrochlear or cervical) were removed under novocaine anesthesia, immediately cut into small bits and ground in a mortar with a small amount of warm saline solution. The resulting emulsion was injected in equal amounts into the right testicles of two normal rabbits. The animals were kept under constant observation. Dark-field examinations were made with specimens from all visible or palpable scrotal or testicular lesions and with all subsequent testicular emulsions used for transfers. Animals which developed no lesions at the end of ninety days were sacrificed and the right testicle of each was removed, emulsified, examined by dark-field and injected intratesticularly into two normal rabbits. No tissue transfer experiment was declared negative until transfers had thus been made through two sets of rabbits.

Our findings are summarized in the following table:

TABLE 1

The recovery of treponemas from lymph nodes in untreated syphilis (tissue transfer method)

\begin{tabular}{c|l|l|l}
\hline History number & \multicolumn{1}{|c|}{ Clinical diagnosis } & \multicolumn{2}{|c}{ Tissue transfer } \\
\cline { 4 - 5 } \cline { 3 - 4 } 11238 & Primary syphilis & $\begin{array}{c}\text { Positive } \\
\text { Positive }\end{array}$ & \\
11806 & Primary syphilis & & Negative \\
11405 & Secondary syphilis (late) & & Negative \\
9655 & Latent syphilis & & Negative \\
11569 & Lạtent syphilis (congenital?) & Negative \\
11890 & Tertiary syphilis (leg ulcers) & & \\
12227 & Tertiary syphilis (skin recurrence) & & Positive \\
10987 & Tertiary syphilis (gumma of knee) & & Negative \\
10829 & Neurosyphilis (tabes dorsalis) & & \\
\hline
\end{tabular}

We conclude from this study that the tissue (lymph node) transfer method of determining the presence or absence of syphilitic virus in experimental infection does not invariably give positive results when applied to patients with proven untreated syphilis. Therefore, in human syphilis the method is unreliable. In a given case negative results before any treatment is instituted is of no diagnostic significance. After treatment is instituted negative results cannot be interpreted as indicating biologic cure. It is suggested that this discrepancy in results with the tissue transfer method in human and experimental syphilis is probably due to 
the fact that in the latter the virus is usually one thoroughly adapted to the rabbit by previous animal passage. Dosage also is probably important and this factor is now being studied by us.

Observations on the Apparent, Adaptability of the Body to Infection, Unusual Hardships, Changing Environment and Prolonged Strenuous Exertion. By BURGESS GoRdon and (by invitation) JoHN C. BAKER, Philadelphia, Pa.

Competitors in a transcontinental foot race (March, April and May, 1928) who walked or ran 3482 miles in 84 consecutive days were studied before, during and after the contest. In histories obtained from 174 contestants a wide variation in age, physical condition, preliminary training and diet was noted. Infections, injuries and experiences common in frontier life of 75 years ago occurred during the race. The chief causes for withdrawal from the contest were so-called "shin splints," resulting from myositis and periostitis. Various fads and fancies in diet were advocated by the runners at the beginning of the race. As the contest progressed, however, meat and certain vegetables could not be supplied as desired. Carbohydrate became the predominant food. Several competitors consumed no meat during the entire race and others none after the first $\mathbf{5 0 0}$ miles. It was noted that carbohydrate in the form of oranges, dates, figs, honey, dextrose and cake between meals was taken by most runners after the first few hundred miles, apparently in order to relieve hunger and fatigue.

Observations made after the race, which included microscopic and chemical studies of the blood and urine, roentgenographic, electrocardiographic, ophthalmoscopic, orthopedic and laryngeal examinations were essentially negative as would be expected from a group of apparently normal individuals who had followed less strenuous forms of exercise. Correspondence during the past eight months shows that 84 contestants have suffered no apparent untoward effects.

In considering the condition of the runners at different periods during the race it would appear that it is extremely difficult to estimate the potential endurance of an individual or to predict the degree of resistance to infection.

A Clinical Metabolic Study of "Obstinate" Cases of Obesity. By Solomon Strouse and (by invitation) C. C. WANG, Chicago, Ill.

This work was undertaken on patients who had resisted supposed strict dietary procedures at home. They were then established in the metabolic clinic at the hospital and placed under complete control. A noticeable contrast was shown and the patients could be made to lose weight mathematically according to schedule.

The Clinical Interpretation of Diabetes. By John R. WILliams, Rochester, N. Y.

The following is an abstract of a study of upwards of five hundred diabetics with reference to a better means of control and interpretation. It is commonly believed that insulin causes the burning or utilization of 1.5 to 2 grams of glucose 
per unit. For the past six years the writer has coöperated with the Eli Lilly Company in the clinical testing of insulin. In this work one patient, whose metabolism is fairly constant, and who is highly trained has been used as a test case. The results obtained have been carefully checked and have invariably corresponded closely with the assays of the Lilly Company. The work which will be reported in a later communication indicates that one unit of insulin causes the utilization of approximately $\mathbf{4}$ grams of glucose, rather than 2 grams as is commonly assumed.

The diet of normal individuals contains from 300 to 800 grams of glucose forming food. One unit of insulin will burn approximately 4 grams of glucose. The normal pancreas makes from $\mathbf{7 5}$ to 200 or more units of insulin daily according to the food intake of the individual. When the pancreas fails to make sufficient insulin to care for the glucose content of the diet, diabetes results. That portion of the glucose which is not utilized and which exceeds the storage capacity of the body will be eliminated as urine sugar. The difference between the amount of glucose ingested and that excreted in the urine is the glucose utilization of the patient. The glucose utilization factor in a well treated case of diabetes is fairly constant and may be increased by the administration of insulin. In either a normal individual or a diabetic the number of grams of glucose utilized, divided by four, will give the number of units of insulin made by the individual. This figure hereafter designated as the insulin coefficient is a fairly constant factor in the diabetic. Example-The diet contains 100 grams of glucose, 20 grams are eliminated in the urine, therefore $\mathbf{8 0}$ grams are utilized. The pancreas makes 20 units of insulin.

To determine the coefficient of a patient taking insulin, the number of units administered must be subtracted from the total number of units required for the utilization of the food. Thus in the above case if the patient were receiving 8 units daily his coefficient would be 20 minus 8 or 12 . Written IC 12 . The insulin coefficient is a fairly constant factor and changes slowly with improvement or decline. It is not materially affected by occasional violations in diet, even in the presence of large amounts of urine sugar and high blood sugar levels, nor is it influenced by insulin administration.

A severe diabetic is one whose insulin coefficient ranges below 20, moderately severe cases range from 20 to 35 , mild cases from 35 to 75 . A diabetic may have a minus coefficient. Example: The diet contains 100 grams of glucose, the urine 20 grams of sugar, 30 units of insulin are being administered daily. Insulin coefficient is -10 . There are several explanations for this minus coefficient. (a) The insulin may be administered in too large a dose, in excess of the body requirements at a given time, and is eliminated in the urine, without serving any useful purpose; or $(b)$ an infection or some other unsuspected disease may be present which destroys insulin; or $(c)$ there may be an error in insulin administration or $(d)$ in diet. The insulin coefficient is a more valuable guide to the progress of an infection in diabetes than is the temperature curve or the leucocyte count. It has 
great prognostic value. It affords a most reliable check on the integrity of the patient who violates his diet or insulin dosage. It is by far the best method of measuring the progress of a case and the efficiency of the treatment. A patient who can raise his coefficient from 5 to 10 units in a year is making satisfactory progress.

In making tests to determine the insulin coefficient, the patient should be thoroughly instructed as to its significance and the necessity for exact coöperation. The diet should be constant for at least three days if possible. The urine should be saved and measured with care. Urine sugars should be accurately determined. A slowly rising midmorning blood sugar indicates that the patient is gradually exceeding his capacity to utilize glucose. The insulin coefficient is a far better method of differentiating spurious diabetes and renal diabetes from true diabetes than is the so-called glucose tolerance test. A glucose tolerance test is about as useful and reliable a method of determining the efficiency of the pancreas as is the "hundred yard dash in eleven seconds" a measure of the physical ability of an individual to walk five miles at a leisurely gait.

At the present time there is no clinical method in use which enables clinicians in one community to compare the efficiency of their methods with the clinicians of another community. - Likewise there is no clinical method in use which enables physicians to accurately contrast or evaluate different therapeutic measures. The insulin coefficient method meets these requ:rements.

Paroxysmal Bundle Branch Block. By BenJAMIN M. BAKER (by invitation) and Edward P. Carter, Baltimore, Md.

An example of paroxysmal bundle branch block will be presented. The patient, when first seen, showed paroxysmal auricular fibrillation and paroxysmal bundle branch block. It was noted that during the periods of delay in intraventricular conduction the cardiac rate was above 85 to the minute. When the rate fell below this figure normal sequential rhythm with normal intraventricular conduction occurred.

Under rest and the administration of digitalis normal sequential rhythm with normal intraventricular conduction was established which constantly altered to bundle branch block when the cardiac rate was appropriately increased by various measures, thus indicating that, at least, one control of the spread of the excitation wave was the auricular rate. Delay in intraventricular conduction occurred both with and without fibrillation of the auricles.

Several galvanometric records will be shown portraying in a single lead transition from normal sequential rhythm with normal intraventricular conduction to bundle branch block.

Studies are now in progress to determine the part played by anoxemia in intraventricular conduction. 